\title{
UKCTOCS update: applying insights of delayed effects in cancer screening trials to the long-term follow-up mortality analysis
}

Matthew Burnell ${ }^{1}$, Aleksandra Gentry-Maharaj ${ }^{1}$, Steven J. Skates², Andy Ryan ${ }^{1}$, Chloe Karpinskyj ${ }^{1}$, Jatinderpal Kalsi ${ }^{3}$, Sophia Apostolidou', Naveena Singh ${ }^{4}$, Anne Dawnay ${ }^{5}$, Robert Woolas ${ }^{6}$, Lesley Fallowfield ${ }^{7}$, Stuart Campbell ${ }^{8}$, Alistair McGuire ${ }^{9}$, Ian J. Jacobs ${ }^{3,10}$, Mahesh Parmar ${ }^{1}$ and Usha Menon ${ }^{1 *}$ (D)

\begin{abstract}
Background: During trials that span decades, new evidence including progress in statistical methodology, may require revision of original assumptions. An example is the continued use of a constant-effect approach to analyse the mortality reduction which is often delayed in cancer-screening trials. The latter led us to re-examine our approach for the upcoming primary mortality analysis (2020) of long-term follow-up of the United Kingdom Collaborative Trial of Ovarian Cancer Screening (LTFU UKCTOCS), having initially (2014) used the proportional hazards (PH) Cox model.

Methods: We wrote to 12 experts in statistics/epidemiology/screening trials, setting out current evidence, the importance of pre-specification, our previous mortality analysis (2014) and three possible choices for the followup analysis (2020) of the mortality outcome: (A) all data (2001-2020) using the Cox model (2014), (B) new data (2015-2020) only and (C) all data (2001-2020) using a test that allows for delayed effects.

Results: Of 11 respondents, eight supported changing the 2014 approach to allow for a potential delayed effect (option C), suggesting various tests while three favoured retaining the Cox model (option A). Consequently, we opted for the Versatile test introduced in 2016 which maintains good power for early, constant or delayed effects. We retained the Royston-Parmar model to estimate absolute differences in disease-specific mortality at 5, 10, 15 and 18 years.

Conclusions: The decision to alter the follow-up analysis for the primary outcome on the basis of new evidence and using new statistical methodology for long-term follow-up is novel and has implications beyond UKCTOCS. There is an urgent need for consensus building on how best to design, test, estimate and report mortality outcomes from long-term randomised cancer screening trials.
\end{abstract}

Trial registration: ISRCTN22488978. Registered on 6 April 2000.

Keywords: UKCTOCS, Follow-up, Mortality analysis, Ovarian cancer, Cancer screening, Delayed effect

\footnotetext{
* Correspondence: u.menon@ucl.ac.uk

Related Article: https://www.thelancet.com/journals/lanonc/article/PIIS1470-2 045(09)70026-9/fulltext

${ }^{1} \mathrm{MRC}$ CTU at UCL, Institute of Clinical Trials and Methodology, University College London, 90 High Holborn, 2nd Floor, London WC1V 6LJ, UK

Full list of author information is available at the end of the article
}

(c) The Author(s). 2021 Open Access This article is licensed under a Creative Commons Attribution 4.0 International License, which permits use, sharing, adaptation, distribution and reproduction in any medium or format, as long as you give appropriate credit to the original author(s) and the source, provide a link to the Creative Commons licence, and indicate if changes were made. The images or other third party material in this article are included in the article's Creative Commons licence, unless indicated otherwise in a credit line to the material. If material is not included in the article's Creative Commons licence and your intended use is not permitted by statutory regulation or exceeds the permitted use, you will need to obtain permission directly from the copyright holder. To view a copy of this licence, visit http://creativecommons.org/licenses/by/4.0/ The Creative Commons Public Domain Dedication waiver (http://creativecommons.org/publicdomain/zero/1.0/) applies to the data made available in this article, unless otherwise stated in a credit line to the data. 


\section{Background}

Randomised controlled trials (RCT) are the cornerstone of the evidence base for clinical management of millions of patients across the world. RCTs evaluating the mortality impact of cancer screening typically involve large numbers of participants followed up over many years, sometimes decades. The general rule in clinical trials is strict adherence to the statistical analysis plan specified prior to unblinding and analysis of outcome data. Sometimes, during continued long-term follow-up of these trials, new understanding based on evidence from other trials and new analytical methods may require reevaluation of the analysis plan.

One important example is the accumulating evidence in cancer-screening trials of a delay of several years before a mortality reduction is observed between the screen and control arms [1-3]. Almost all the cancerscreening trials, breast [4-14], prostate, colorectal, and lung [15-31] in their graphic representation of diseasespecific mortality over time have reported a delayed difference (if present) between screen and control arms (Table 1). Most have an initial time window in the first several years after start of screening during which there is little or no mortality reduction, followed by one in which the reduction becomes evident [2]. These findings are in keeping with our understanding of how screening works. It reduces deaths by detecting cancers early, before they reach an incurable state. It is less likely to prevent cancer deaths occurring in the early years post randomisation as there is little chance to detect these cancers sufficiently early in their natural history. However, almost none of these cancer-screening trials have used analytical methods which formally allow for a non-constant effect (non-proportional hazards). All have described the screening effect using relatively simple methods, usually a single Poisson-based rate ratio (RR) $[4,12,24,30,34,35]$ or Cox model with a single hazard ratio $(\mathrm{HR})$ estimate $[18,22]$. A single $\mathrm{HR}$ is only appropriate if the reduction in hazard rates is relatively immediate and constant over time. In screening trials, such estimates cannot reliably describe the changing effects of screening on mortality over time.

Alongside, new analytical methods have been developed for trials lacking treatment proportionality. Tests that combine evidence from more than one aspect of the data have gained popularity as a way to mitigate the effects of potential but unknown non-proportionality of hazards, although some may work best in a specific scenario. The "joint test" appears in simulations to be preferentially beneficial under late effects $[38,39]$ whilst the "combined test" appears to be preferentially beneficial under early effects [40, 41]. Another recent addition is the Versatile test [42], which seeks to cover all bases by combining three (weighted) log-rank tests giving good power for the test under early effects, proportional hazards $(\mathrm{PH})$ and late effects, respectively. These tests are likely better suited than the Cox model for analysis of outcomes which are non-proportional across the duration of a trial.

In the United Kingdom Collaborative Trial of Ovarian Cancer Screening (UKCTOCS) too, the initial mortality analysis in 2014 used a PH Cox model and reported an average mortality reduction estimate. However, given the growing external evidence, there have been extensive discussions within the UKCTOCS trial committees to ensure the outcome data is analysed appropriately. We believe that this issue will be important for any longterm cancer screening trial. The Cox model, while valid, could be viewed as restrictive and failing to utilise the most appropriate analytical approach, given the delayed mortality reductions seen in many screening trials across a range of cancers (Table 1) $[14,17,24,31]$. Furthermore, retention of the Cox model based on prespecification may result in suboptimal interpretation of UKCTOCS data and therefore an abrogation of our responsibility to the huge collective investment by the trial volunteers, the funding agencies, charities, the National Health Service (NHS), researchers and most importantly women who develop ovarian cancer in the future. This is balanced by a concern that changes to the 2014 analysis plan could be controversial and lead to criticism of cherry-picking methodology that gives the "best" test result.

Many trialists may face similar dilemmas, when new evidence suggests that trial design, conduct or analysis may need to be amended. Decisions are often made by the Trial Management Committee (TMC) with input from independent oversight bodies such as a Trial Steering (TSC) or Scientific Advisory (SAC) Committees. We report on the process we undertook in UKCTOCS to re-examine our approach for the upcoming analysis (2020) of the primary mortality outcome at the end of extended follow-up and how we addressed the issue of delayed effects.

\section{Methods}

Between 2001 and 2005, 202,638 postmenopausal women aged 50-74 were recruited to UKCTOCS. They were randomised to screening using a longitudinal serum CA125 algorithm (multimodal group, MMS, 50, 640), transvaginal ultrasound (ultrasound group, USS, 50,639 ) or no screening (control group, $C, 101,279$ ) as described previously [43-45]. Women in the screen groups underwent screening until the end of 2011 and received a median of nine annual screens. At median follow-up of 11.1 years (administrative censorship 31 Dec 2014), a higher proportion of women were diagnosed with low-volume (stages I, II and IIIa) tubo- 


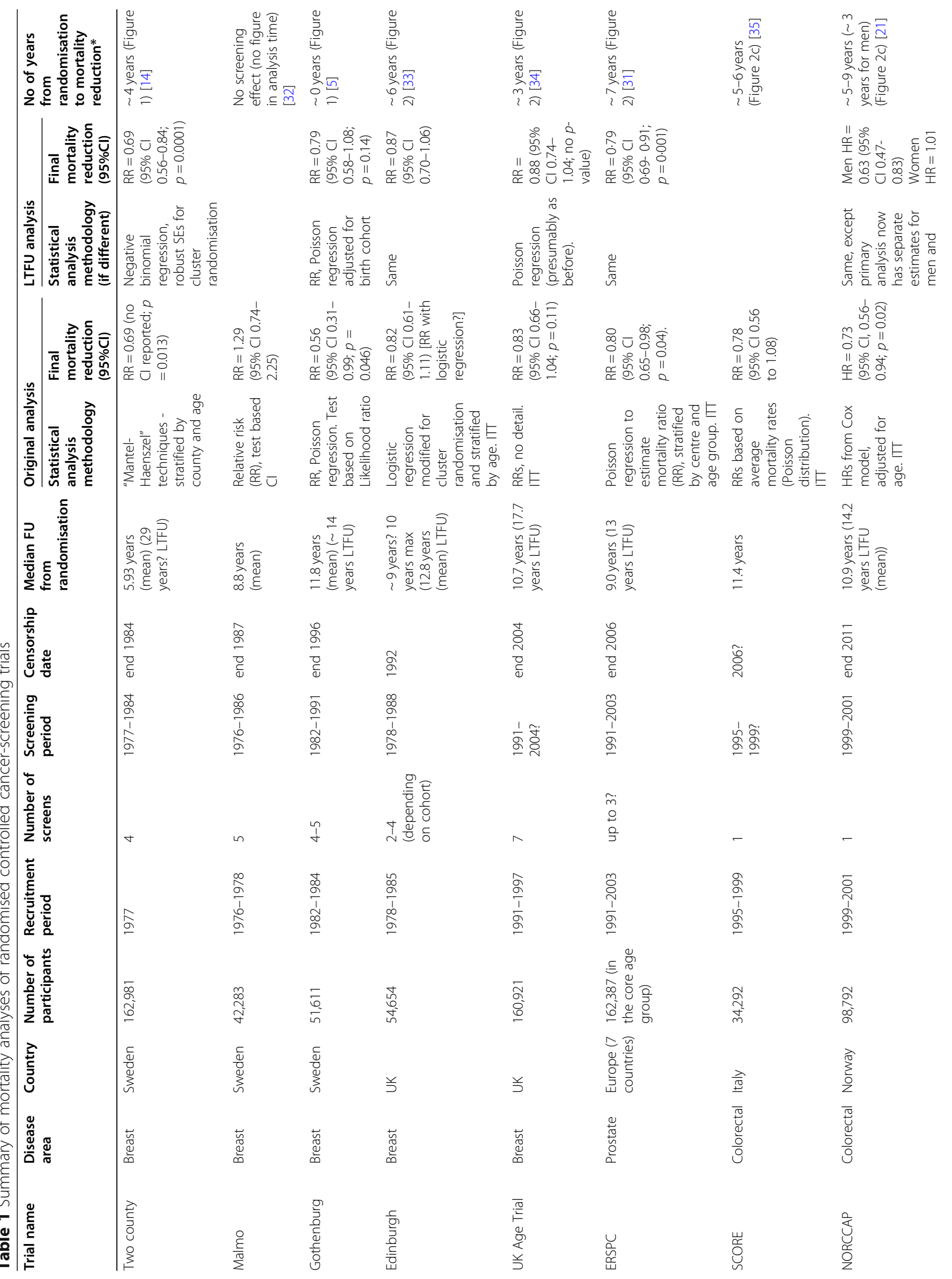




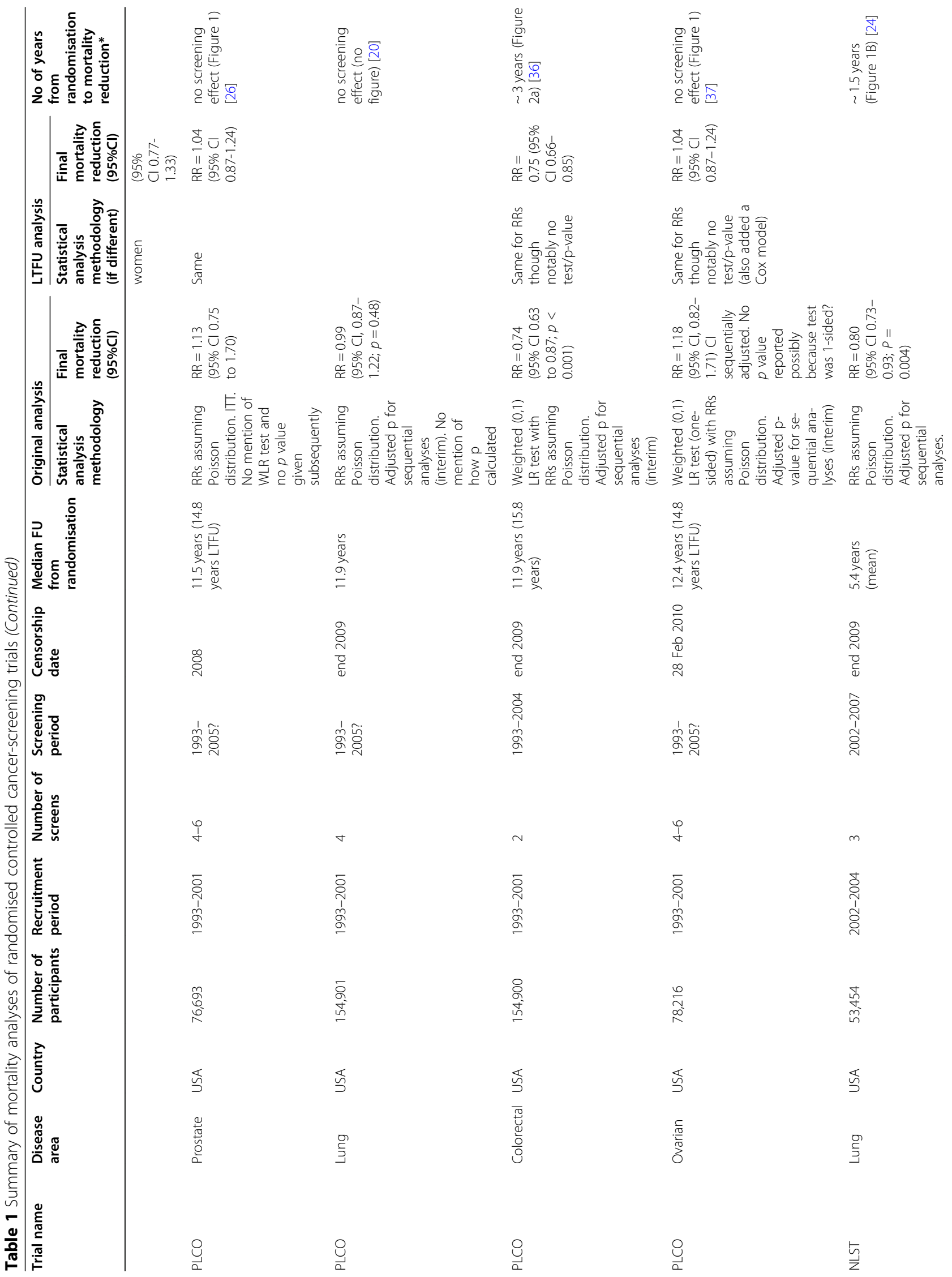


Burnell et al. Trials $\quad$ (2021) 22:173

Page 5 of 12

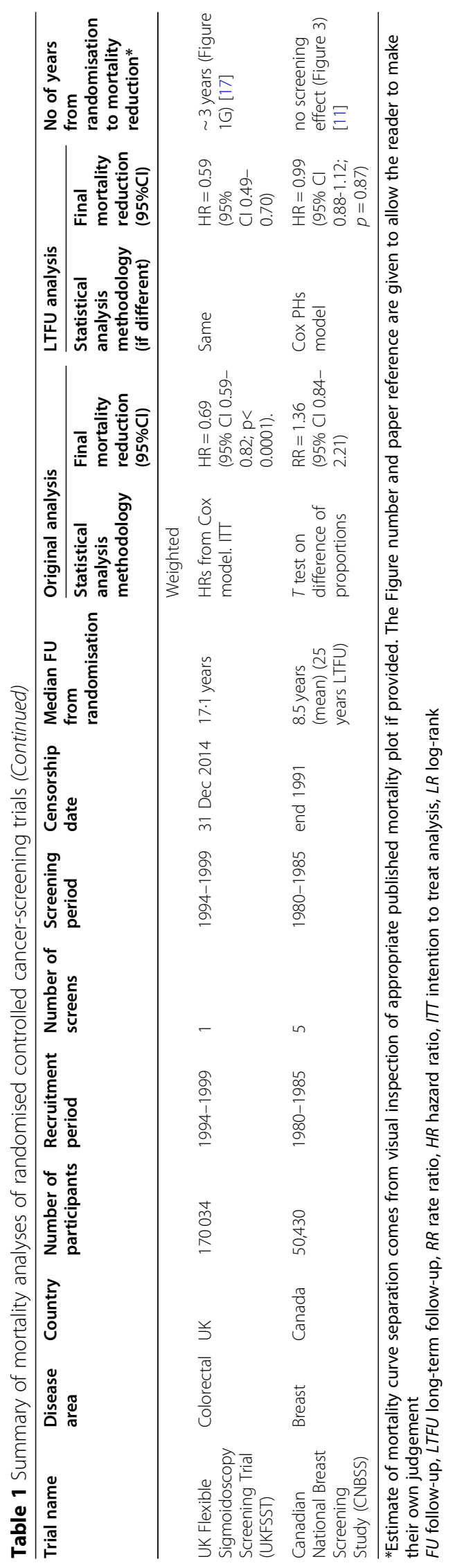


ovarian cancer in the MMS (40\%; $p<0.0001)$ compared to the $C(26 \%)$ group. The Cox model indicated a trend to mortality reduction in favour of MMS (HR 0.85; 95\% CI 0.70-1.03, $p=0.10$ ) and USS (HR 0.89; 95\% CI $0.73-1.07, p=0.21$ ), which was not statistically significant at the 5\% level. A Royston-Parmar (RP) flexible parametric model showed that HR varied over time. In the MMS group, it was 0.92 (95\% CI 0.69-1.20) in years $0-7$ and 0.77 (95\% CI $0.54-0.99$ ) in years $7-14$. In the USS group, it was 0.98 (95\% CI $0.74-1.27)$ in years $0-7$ and 0.79 (95\% CI $0.58-1.02)$ in years 7-14 [43]. Followup was extended to 30 June 2020 to assess the long-term mortality impact (LTFU UKCTOCS) [43, 46]. Final receipt of death data from the registries is anticipated by the end of September 2020, with unblinding and analysis planned for November 2020.

To ensure independent input into our statistical conundrum, the TMC proposed seeking the views of a broad panel of international experts with statistical and screening trial expertise who had not been involved in any aspect of UKCTOCS. The process was developed through detailed discussions with the independent members of the TSC. In September 2019, 12 experts (Table 2) were approached by the Trial Statistician for advice. They were sent a letter briefly describing UKCTOCS together with a summary of the current evidence from other cancer-screening trials, importance of prespecification and our 2014 mortality analysis results. Three potential options for the primary analysis of the extended follow-up data developed with the TSC were described sequentially, each including possible pros and cons, in a neutral manner. These were:
A) Analyse all outcome data (2001-2020) using the PH Cox model of the original UKCTOCS analysis, representing the pre-specification viewpoint.

B) Analyse only the outcomes that occurred since the original censorship (31 December 2014), either assuming $\mathrm{PH}$ or not, to address the view that data should not be re-used, without formal statistical accommodation for multiple analyses.

C) Model all outcome data using a method of analysis and model that allows for a late effect of screening on mortality and reflects current understanding of cancer-screening trials-a pragmatic evidential approach. The specific model suggested for $(C)$ was the RP model [47] as it had been used as a secondary analysis method for the 2014 analysis [43].

Experts were asked to critique and state a preference or suggest another option (Supplementary Materials 1). Results were collated and summarised based on (1) indicated choice of A, B, C or other and (2) pertinent comments provided.

\section{Results}

In total, 12 individuals were contacted from the UK (5), the USA (5), Canada (1) and Belgium (1) and 11 responded (see acknowledgement). Their anonymised responses can be found in Table 2 and Supplementary Table 1.

Eight (73\%) of the 11 experts recommended changing the pre-specified analysis to one that more appropriately allows for a delayed effect (Table 2). EX4 was not troubled by the shift from a pre hoc to post hoc decision-

Table 2 Summary of experts' choices and their additional suggestions if not in concordance with A, B or C

\begin{tabular}{|c|c|c|c|}
\hline Expert & Expertise & Choice & Additional suggestions \\
\hline EX1 & Biostatistics, public health & A & Suggests only include cancers diagnosed from period of intervention. \\
\hline EX2 & $\begin{array}{l}\text { Biostatistics, clinical trials and } \\
\text { cancer research }\end{array}$ & A & \\
\hline EX3 & Statistics & A & $\begin{array}{l}\text { Ticked "alternative" but suggested hybrid of A for testing and C for estimation- } \\
\text { interpreted as A }\end{array}$ \\
\hline EX4 & $\begin{array}{l}\text { Cancer epidemiology, prevention } \\
\text { and screening }\end{array}$ & $\begin{array}{l}\text { Change } \\
\text { analysis }\end{array}$ & Suggested "number needed to screen". \\
\hline EX5 & Biostatistics, cancer epidemiology & $\begin{array}{l}\text { Change } \\
\text { analysis }\end{array}$ & $\begin{array}{l}\text { Did not complete form but indicated choice by email, test based on difference of } \\
\text { restricted mean survival time (RMST). }\end{array}$ \\
\hline EX6 & Biostatistics and epidemiology & $\begin{array}{l}\text { Change } \\
\text { analysis }\end{array}$ & $\begin{array}{l}\text { Suggested splitting data into yearly bins and assess HR in each, possibly with smoothing. } \\
\text { Avoid single HR. }\end{array}$ \\
\hline EX7 & $\begin{array}{l}\text { Biostatistics, clinical trials and } \\
\text { cancer research }\end{array}$ & C & $\begin{array}{l}\text { Did not complete form but indicated choice by email. Prefers more parsimonious model } \\
\text { with interpretable parameters. }\end{array}$ \\
\hline EX8 & Biostatistics, clinical trials & C & \\
\hline EX9 & Biostatistics, public health & C & Prefers more parsimonious model with interpretable parameters. \\
\hline EX10 & Cancer epidemiology, public health & C & Also suggests "versatile weighted log-rank test" \\
\hline EX11 & Statistics, public policy & C & \\
\hline EX12 & Biostatistics & - & Did not respond within timeframe \\
\hline
\end{tabular}


"reason" should have a role in science. Similarly, EX8 argued "a conclusion should be reached based on a proper consideration of the full evidence" and use scientific principles-"full information from data should be extracted". Indeed, rather than viewing it as "data-dredging" or "changing the endpoint", EX8 described this approach as just "using common sense". EX9 felt the lack of (complete) pre-specification a weakness, but not "a violation of good scientific principles". For "a major and definitive screening trial ..... such regulatory constraints should not be the primary consideration" but instead "approximating the truth as well as possible". EX11 was not persuaded by the pre-specification argument and claimed keeping a plan that is less preferable "turns research rules into an irrational, mindless, and restricting obsession with methodological procedure"; "rules have a purpose, but when the higher priority is understanding phenomena in a reasoned disciplined way... then a compelling argument can be made to deviate from them". EX11 stated that no screening trial has shown an immediate effect and appealed to the common sense of the scientific audience; "we can discern the difference in attempts by a study team to game the analysis to gain statistical significance, from a good faith effort to apply a statistical technique that is more appropriate for the data". Different screening trials will have different results and delayed effects, all dependent on differing facets of trial design and the cancer itself, the effects of which are largely unknown until we do the study. "Point is, we are still learning how to design and analyse RCT screening trial data."

Three of the eleven (EX2, EX3, EX1) believed that we should retain the initial analysis approach (option A). This was based on the pre-specification argument"avoids the appearance of trying to get a significant result by changing the test" (EX2), "maintains credibility in the scientific community" (EX3), "most likely to be accepted as valid by the cancer research and policy community" (EX1). However, EX1 did suggest modifying the pre-specified plan to limit analysis to only cancers diagnosed within the screening period.

Of the eight who suggested changing the pre-specified analysis, five (EX7, EX8, EX9, EX10 and EX11) explicitly selected approach $C$ (using all acquired outcome data and a model that allows for delayed effects). While there were positive comments about the suggested RP model (credibility due to pre-specification $E X 7$, informative of the screening effect over time EX9), none gave a clear endorsement of this approach. The main reason was interpretability (EX7, EX9, EX4,EX6). EX10 noted that power was little studied under various "flavours" of nonPHs, and suggested separating testing from estimation, opting for a versatile weighted log-rank test for the former. EX4 and EX6 formally indicated an alternative option. EX6's preference was for dividing the data into yearly bins and estimating the HR in each, possibly with some smoothing. EX6 argued extensively we should avoid a single HR estimate, which will provide "a very blurred, incomplete and misleading picture of how much/little good screening did for the 100,000 participants screened, or of how much future women might expect from a screening regimen based on these screening tools." EX4 stated that the number needed to screen was the most suitable measure for a screening study. EX5 recommended a test based on the difference of restricted mean survival times (RMST) which "does not need any modelling and the results can be interpreted easily clinically".

None of the 11 responders chose approach B. This was mainly because it did not use the full dataset. In addition, there were concerns that it could lead to "unfavourable early results" (important data) being censored (EX11) and a "disconnected" HR (EX6).

Based on the feedback, we decided to change the primary analysis test for LTFU UKCTOCS. Table 3 summarises the major pros and cons of available approaches to dealing with non-PH in terms of tests. We used two main criteria to choose the specific test-(1) minimal a priori specification on the specific form of the mortality difference over time (2) able to accommodate delayed effects while maintaining good power in a variety of potential scenarios. Based on these criteria, we opted for the Versatile test [16], suggested by EX10. The RP model was retained to estimate absolute differences in diseasespecific mortality at 5, 10, 15 and 18 (our estimate of the upper limit of reliable follow-up given administrative censorship on 30 June 2020) years. Options A and B were included as secondary analyses of the primary mortality outcome. These amendments were incorporated into the statistical analysis plan (20 February 2020), which was endorsed by the independent TSC.

\section{Discussion}

Given the now large body of evidence of a delay in mortality reduction in long-term cancer-screening randomised trials, and the majority view of independent statistical, epidemiological and screening trial experts, we altered the approach for our primary mortality analysis for the LTFU from that used for our 2014 analysis. The new approach allows for a delayed effect in contrast to our previous analysis which assumed a constant screening effect. There were a variety of opinions on the specific test which suggests an urgent need for consensus building on how best to design, analyse and report mortality outcomes in cancer-screening trials.

Our decision to change the statistical analysis plan for extended follow-up is a significant decision. The large 
Table 3 Summary of pros and cons of potential statistical tests that could be used when there is a time varying mortality difference (non-proportional hazards)

\begin{tabular}{lll}
\hline Method & Pros & Cons \\
\hline Weighted log-rank test & Not model-based & Need to formally pre-specify the expected mor- \\
tality differences over time (functional form of & the HR) for the test to have statistical validity. & This may prove difficult given that differences \\
& & will depend on the natural history of the cancer, \\
screening strategy, number of screens, years of & follow-up, etc.
\end{tabular}

Known to improve power in situations of non$\mathrm{PH}$

Most widely used and established test for non$\mathrm{PHs}$ in clinical trials

Flexible parametric model such as the RoystonParmar (RP) model (cubic splines) or fractional polynomial (FP) survival model (joint test of all screen arm related terms)

Weibull model (with separate shape parameters for group)

Cox model with time varying coefficient (TVC)

Difference in restricted mean survival time (RMST)
No need to pre-specify specific functional form of the mortality effect

Can mimic a non-PH function to almost arbitrary degree.

Allows one to accurately describe the hazards and their ratio over time.

Relatively easy to fit

Can reflect simple time-varying differences in mortality curves succinctly

Easy to fit

Extension of Cox model, so perhaps more readily acceptable given prior use

Able to incorporate non-PHs without specifying differences in mortality curves (functional form). For example, choose linear function of time, then time-varying effect could be linear decreasing or increasing.

No need to consider baseline hazard function

No need to be model-based, can use nonparametric estimation.

Can reflect any time-varying difference in mortality - estimate of RMST difference graphically corresponds to the difference in area between the respective survival curves.

Do not need to speculate on particular form of time varying difference in mortality. However choice of time restriction may depend on expectation of difference (HR functional form).

Gives a meaningful single summary estimate
There is an associated risk of mis-specifying the form of the HR, and simulations suggest incorrectly assuming a late effect, for example, may incur a greater penalty than assuming $\mathrm{PH}$ under early or late effects $[33,47]$.

Subjects' deaths are given a differential (and arbitrary) weighting which may be hard to justify. A further conceptual problem with weights based on the data is that if a trial subsequently reports again, the weight allocated to each event will change, likely significantly.

No precedence for use as primary analysis in RCTS

Flexibility makes it easy to over fit and include random data artefacts.

Power properties not well known. Will lose power with too many model parameters.

Need to pre-specify number of knots/degrees of freedom and placement of knots for RP model. FP model requires choice of selection of powers and degree. Can be guided by information criteria but then data dependent, and may reflect artefacts.

Test, as proposed, considers if mortality curves are "different". Significant result could theoretically result from crossing curves, even curves with no difference in area under the curve.

Unlikely to capture more complex curves sufficiently. All hazard functions must be monotonic (constant decrease or increase)

Need to pre-specify function of time that the non-PHs apply to-usually a simple linear or log function of time

Interpretation not straightforward

Awkward and (very) time-consuming to fit (splits data at each failure)

No definite agreement on test of significance. Could be similar to the joint test on 2 degrees of freedom.

Need to pre-specify choice of time restriction, possibly including initial time to, as well as final time limit $t 1$.

May be time consuming to estimate, including standard error.

As the test looks for differences in area under 
Table 3 Summary of pros and cons of potential statistical tests that could be used when there is a time varying mortality difference (non-proportional hazards) (Continued)

\begin{tabular}{|c|c|c|}
\hline Method & Pros & Cons \\
\hline & even with non-PHs & $\begin{array}{l}\text { the curve, survival curves that come back } \\
\text { together can result in a significant test result. }\end{array}$ \\
\hline \multirow{4}{*}{$\begin{array}{l}\text { Combined test (of Cox test with a permutation } \\
\text { test based on RSMTs on } 2 \mathrm{df} \text { ) }\end{array}$} & \multirow{3}{*}{$\begin{array}{l}\text { Simulations suggest power not much lower } \\
\text { than Cox alone under PHs and more powerful } \\
\text { in more situations than joint test }[33,47] \text {. }\end{array}$} & Difficult to explain \\
\hline & & Time-consuming to fit (permutation test). \\
\hline & & $\begin{array}{l}\text { Issues of RMST (see above)_choice of time } \\
\text { restriction }\end{array}$ \\
\hline & Enhanced power for early effect & Simulations suggest not powerful for late effects \\
\hline \multirow[t]{2}{*}{$\begin{array}{l}\text { Joint test (of Cox proportional screen arm effect } \\
+ \text { Grambsch-Thurneau non-PH test on } 2 \mathrm{df} \text { ) }\end{array}$} & $\begin{array}{l}\text { Test based on results of the Cox model (screen } \\
\text { arm effect and the Schoenfeld residuals), so } \\
\text { perhaps more readily acceptable given prior use } \\
\text { of the Cox model }\end{array}$ & $\begin{array}{l}\text { Simulations suggest better under late effects but } \\
\text { not good power for early effects }[33,47] \text {. }\end{array}$ \\
\hline & $\begin{array}{l}\text { Relatively simple test (with degree of } \\
\text { intuitiveness), but more powerful than just } \\
\text { screen arm effect under non-PHs }\end{array}$ & \\
\hline \multirow{3}{*}{$\begin{array}{l}\text { Combination tests such as Versatile Test } \\
\text { (maximum test statistic of } 3 \text { weighted tests- } \\
\text { early, PHs, late effects) or "max-combo" (also } \\
\text { includes "middle" effects) }\end{array}$} & Not model-based & $\begin{array}{l}\text { Appears complicated (need for reference to a } \\
\text { correlated multivariate z-distribution for test } \\
\text { statistic) }\end{array}$ \\
\hline & $\begin{array}{l}\text { Provides good power in all situations, covers } \\
\text { bases with small price in efficiency }\end{array}$ & Not the most powerful test. \\
\hline & $\begin{array}{l}\text { Best choice if one wants to be agnostic of } \\
\text { specifying the time varying mortality difference }\end{array}$ & $\begin{array}{l}\text { Can feasibly reject the null hypothesis both in } \\
\text { favour of the study arm and of the control arm } \\
\text { using the same data. }\end{array}$ \\
\hline
\end{tabular}

majority of the published cancer-screening trials $[17,25$, $26,31,33,34]$ have retained the same primary mortality analysis methodology for both their initial and extended follow-up analysis (Table 1). The only exceptions we found were the Two County trial which used negative binomial regression [14] for follow-up analysis in place of Mantel-Haenszel stratified risk-ratios [12] and the Norwegian Colorectal Cancer Prevention Trial (NORCCAP) which changed the primary analysis from overall population to subgroups based on gender [21]. In the Two County trial, whilst no explanation was given, the change was not substantive; both initial and follow-up methods estimated risk ratios. For NORCCAP, "because substantial heterogeneity existed between women and men, the steering committee decided to present results for women and men separately", which may be argued as a significant post hoc data-driven amendment. None of the trials as far as we are aware sought independent expert opinion. In contrast, we undertook an external consultation. Although the independent expert panel was not unanimous, the majority concluded that a rational argument for revision outweighs that of procedure and pre-specification, and recommended choosing the most appropriate test that allows for a delayed effect. We accepted the view of EX7 that one should "do what you yourselves think is the most effective and secure analysis of all your data, bearing in mind the current state of information about the field." There will be debate about our decision, which we welcome, given the broader implications.

A number of factors contribute to a delayed mortality effect. In the early trial-years, the absolute death rates are low as a result of eligibility criteria which exclude women with cancer diagnosis. The time interval for an individual to be diagnosed with cancer after joining the trial and then dying of the disease also contributes to the delay in separation of the mortality curves. Additionally, the impact of screening on cancers detected at the initial prevalence screen is reduced, as these are necessarily more advanced when screen-detected compared to screen-detected cancers in later years. The performance of most screening strategies improves over time as the number of screens accumulate and the teams involved become more experienced. This is magnified when longitudinal biomarker algorithms are used, as they are based on detecting change from baseline. Conversely, the length of follow-up after end of screening may reduce the mortality difference as follow-up nears conclusion, as the longer the interval, the greater the dilution of screen-detected cancers by cancers that develop after the end of screening [34].

The PLCO colorectal [29] and ovarian [19] trials used a test that has better power for the delayed effect described above. Both used the weighted log-rank test, which is perhaps the best known method for improving power in such situations. However, it requires correctly 
anticipating the specific form of the mortality difference over time, which will depend on the natural history of the cancer, screening strategy, number and frequency of screens and years of follow-up. We have chosen the Versatile test [42], introduced in 2016, which does not require pre-specification of the mortality difference over time. It combines three (weighted) log-rank tests appropriate for capturing early effects, $\mathrm{PH}$ and delayed effects, respectively. It is therefore versatile enough to maintain good power in all potential scenarios, rather than optimal in any given scenario.

Unlike other trials, including the PLCO colorectal [29] and ovarian [19] trials, who measured the screening effect using a single "averaged" rate-ratio, we will use a flexible parametric model to estimate absolute differences in disease-specific mortality at 5, 10, 15 and 18 years. This is in keeping with the growing view that to adequately describe what might be achieved with a particular cancer screening strategy, a more comprehensive set of time-specific measures needs to be reported. Hanley et al. has extensively re-analysed cancer screening trial data and shown that a one-number summary measure systematically dilutes the estimate of mortality reduction that results from screening [2]. In the most recent re-analysis involving breast cancer screening data from Funen, Denmark, the average mortality reduction was $18 \%$ using a $\mathrm{PH}$ model and ranged from 0 to $30 \%$ when a non-PH model was used that considered the impact at different points over time. The reductions were largest for periods where sufficient time had elapsed for the impact to manifest [48]. It is important to note that our estimates of screening efficacy will not necessarily capture the screening effect of a screening program, where participants would likely start screening at age 50 and continue for possibly 25 years. However, once results of our primary analysis are published, it will be possible for groups around the world to use our data to model effectiveness over a longer timeframe and in multiple settings.

The key strength of our approach is the independent and transparent process we have adopted to address a challenging issue and the criteria we used to choose a new specific approach. This involved accommodating delayed effects while maintaining good power in a variety of potential scenarios and requiring minimal a priori speculation on the specific form of the mortality difference over time. A limitation is that given the orthodoxy surrounding pre-specification for analysis of trials, we have retained the original Cox model with an averaged HR over time as an estimate for our secondary analysis.

The screening community is only beginning to understand the challenges posed by long-term cancerscreening trials. Mortality reductions may have been underestimated across cancer types by not considering their timing. Given the importance of early detection in many national cancer strategies, we hope our report will accelerate much needed consensus building on how best to design, analyse and report trials testing cancer screening strategies-as it is clear our currently accepted and widely used methods are insufficient. We also hope it will encourage debate and transparency on how advances in understanding and new analytical methods can be evaluated and incorporated into long-term trials.

\section{Supplementary Information}

The online version contains supplementary material available at https://doi. org/10.1186/s13063-021-05125-8.

Additional file 1: Supplementary Material 1. Cover Letter to Independent International Expert panel, Outline of Options, Comment Form. Supplementary Table S1. Summary of Responses from Independent International Group.

\section{Abbreviations}

UKCTOCS: United Kingdom Collaborative Trial of Ovarian Cancer Screening; LTFU UKCTOCS: Long-term follow-up of the United Kingdom Collaborative Trial of Ovarian Cancer Screening; RCT: Randomised controlled trial; RR: Rate ratio; HR: Hazard ratio; Cl: Confidence interval; $\mathrm{PH}$ : Proportional hazards; TMC: Trial Management Committee; TSC: Trial Steering Committee; SAC: Scientific Advisory Committee; MMS: Multimodal group; USS: Ultrasound group; RP: Royston-Parmar model; NORCCAP: Norwegian Colorectal Cancer Prevention Trial; PLCO: Prostate, Lung, Colorectal and Ovarian Cancer Screening Trial

\section{Acknowledgements}

We are hugely grateful to the international panel of experts (Professor Marc Buyse, Professor David Cox, Professor Stephen Duffy, Professor Mitch Gail, Professor Jim Hanley, Professor David Harrington, Professor Patrick Royston, Professor David Schoenfeld, Professor Robert Smith, Professor David Speigelhalter, Professor $\sqcup$ Wei) who have contributed their time and expertise. We are also indebted to the insights and support provided by the members of the Trial Steering Committee-Professor Henry Kitchener (Chair), Professor Julietta Patnick, Professor Jack Cuzick and Ms. Annwen Jones. We thank all 202,638 volunteers without whom the trial would not have been possible and all the staff involved in this trial for their hard work and dedication.

\section{Disclaimer}

The views expressed are those of the authors and not necessarily those of the NHS, the NIHR or the Department of Health and Social Care.

\section{Authors' contributions}

The process was conceived following many discussions within the TMC involving all authors. MP and UM supervised the study. MB performed the literature search. MB, SJS, AMCG and MP proposed the statistical analysis options with further input from JC (TSC). The survey was drafted by $M B$, AGM, MP and UM with input from IJJ, AMCG and SJS. AGM, AR and MB collated the results and $\mathrm{MB}$ undertook analysis. All contributed to data interpretation. MB prepared the tables. MB, AGM and UM drafted the manuscript. AMcG, LF, SA, JK, RW, IJJ, MP and SJS helped revise the draft. All authors critically reviewed the manuscript and approved the report before submission.

\section{Funding}

The LTFU UKCTOCS is supported by National Institute for Health Research (NIHR HTA grant 16/46/01), Cancer Research UK (CRUK) and The Eve Appeal. UKCTOCS was funded by Medical Research Council (G9901012 and G0801228), CRUK (C1479/A2884), and the Department of Health, with additional support from The Eve Appeal. Researchers at UCL are supported 
by the NIHR University College London Hospitals (UCLH) Biomedical Research Centre and MRC CTU at UCL core funding (MR_UU_12023).

\section{Availability of data and materials}

Table 2 and Supplementary Table 1 contain the exact comments provided by the experts.

\section{Ethics approval and consent to participate}

The initial study was approved by the UK North West Multicentre Research Ethics Committees (North West MREC 00/8/34) on 21 June 2000 with sitespecific approval from the local regional ethics committees and the Caldicott guardians (data controllers) of the primary care trusts. The long-term followup amendment was approved on 24 January 2017 and the amended protocol including the new statistical plan was approved on 12 May 2020. All trial participants provided written informed consent.

\section{Consent for publication}

All authors have seen the final version of the manuscript and give their consent for publication.

\section{Competing interests}

UM has stocks in Abcodia Ltd. awarded to her by UCL. SJS and IJJ are coinventors of the Risk of Ovarian Cancer Algorithm (ROCA) that has been licensed to Abcodia Ltd. by Massachusetts General Hospital (MGH) and Queen Mary University of London (QMUL). IJJ has a financial interest in Abcodia Ltd as a shareholder and director. IJJ and SJS are entitled to royalty payments via MGH and QMUL from any commercial use of the ROCA. All other authors declare no competing interests.

\section{Author details}

${ }^{1}$ MRC CTU at UCL, Institute of Clinical Trials and Methodology, University College London, 90 High Holborn, 2nd Floor, London WC1V 6LJ, UK. ${ }^{2} \mathrm{MGH}$ Biostatistics, Massachusetts General Hospital and Harvard Medical School, 55 Fruit Street, Boston, MA 02114, USA. Department of Women's Cancer, Institute for Women's Health, University College London, 84-86 Chenies Mews, London WC1E 6HU, UK. ${ }^{4}$ Department of Pathology, Barts Health National Health Service Trust, The Royal Hospital, Whitechapel Rd, London E1 1BB, UK. ${ }^{5}$ Department of Clinical Biochemistry, Barts Health National Health Service Trust, Barts Health, 4th floor, Pathology and Pharmacy, 80 Newark St, London E1 2ES, UK. ${ }^{6}$ Department of Gynaecological Oncology, Queen Alexandra Hospital, Cosham, Portsmouth, Hampshire PO6 3LY, UK. ${ }^{7}$ Sussex Health Outcomes Research and Education in Cancer, Brighton and Sussex Medical School, University of Sussex, Science Park Road, Falmer, Brighton BN1 9RX, UK. ${ }^{8}$ Create Health, 150 Cheapside, London EC2V 6ET, UK. ${ }^{9}$ Department of Social Policy, London School of Economics, Houghton Street, London WC2A 2AE, UK. ${ }^{10}$ University of New South Wales, Sydney, NSW 2052, Australia.

\section{Received: 18 August 2020 Accepted: 11 February 2021} Published online: 01 March 2021

\section{References}

1. Etzioni RD, Thompson IM. What do the screening trials really tell us and where do we go from here? Urol Clin North Am. 2014;41(2):223-8.

2. Hanley JA. Measuring mortality reductions in cancer screening trials. Epidemiol Rev. 2011;33:36-45.

3. Hanley JA, McGregor M, Liu Z, et al. Measuring the mortality impact of breast cancer screening. Can J Public Health. 2013;104(7):e437-42.

4. Bjurstam N, Bjorneld L, Duffy SW, et al. The Gothenburg breast screening trial: first results on mortality, incidence, and mode of detection for women ages 39-49 years at randomization. Cancer. 1997;80(11):2091-9.

5. Bjurstam N, Bjorneld L, Warwick J, et al. The Gothenburg Breast Screening Trial. Cancer. 2003;97(10):2387-96.

6. Frisell J, Eklund G, Hellstrom L, et al. The Stockholm breast cancer screening trial--5-year results and stage at discovery. Breast Cancer Res Treat. 1989; 13(1):79-87.

7. Frisell J, Eklund G, Hellstrom L, et al. Randomized study of mammography screening--preliminary report on mortality in the Stockholm trial. Breast Cancer Res Treat. 1991;18(1):49-56.
8. Frisell J, Lidbrink E, Hellstrom L, et al. Followup after 11 years--update of mortality results in the Stockholm mammographic screening trial. Breast Cancer Res Treat. 1997;45(3):263-70.

9. Miller AB, To T, Baines CJ, et al. The Canadian National Breast Screening Study: update on breast cancer mortality. J Natl Cancer Inst Monogr. 1997. https://doi.org/10.1093/jncimono/1997.22.37(22):37-41.

10. Miller AB, To T, Baines CJ, et al. Canadian National Breast Screening Study-2: 13-year results of a randomized trial in women aged 50-59 years. J Natl Cancer Inst. 2000;92(18):1490-9.

11. Miller AB, Wall C, Baines CJ, et al. Twenty five year follow-up for breast cancer incidence and mortality of the Canadian National Breast Screening Study: randomised screening trial. BMJ. 2014;348:g366.

12. Tabar L, Fagerberg CJ, Gad A, et al. Reduction in mortality from breast cancer after mass screening with mammography. Randomised trial from the Breast Cancer Screening Working Group of the Swedish National Board of Health and Welfare. Lancet. 1985;1(8433):829-32.

13. Tabar L, Vitak B, Chen HH, et al. The Swedish Two-County Trial twenty years later. Updated mortality results and new insights from long-term follow-up. Radiol Clin N Am. 2000;38(4):625-51.

14. Tabar L, Vitak B, Chen TH, et al. Swedish two-county trial: impact of mammographic screening on breast cancer mortality during 3 decades. Radiology. 2011;260(3):658-63.

15. Andriole GL, Crawford ED, Grubb RL 3rd, et al. Mortality results from a randomized prostate-cancer screening trial. N Engl J Med. 2009;360(13):1310-9.

16. Andriole GL, Crawford ED, Grubb RL 3rd, et al. Prostate cancer screening in the randomized Prostate, Lung, Colorectal, and Ovarian Cancer Screening Trial: mortality results after 13 years of follow-up. J Natl Cancer Inst. 2012; 104(2):125-32

17. Atkin W, Wooldrage K, Parkin DM, et al. Long term effects of once-only flexible sigmoidoscopy screening after 17 years of follow-up: the UK Flexible Sigmoidoscopy Screening randomised controlled trial. Lancet. 2017; 389(10076):1299-311.

18. Atkin WS, Edwards R, Kralj-Hans I, et al. Once-only flexible sigmoidoscopy screening in prevention of colorectal cancer: a multicentre randomised controlled trial. Lancet. 2010;375(9726):1624-33.

19. Buys SS, Partridge $E$, Black $A$, et al. Effect of screening on ovarian cancer mortality: the Prostate, Lung, Colorectal and Ovarian (PLCO) Cancer Screening Randomized Controlled Trial. JAMA. 2011;305(22):2295-303.

20. Hocking WG, Hu P, Oken MM, et al. Lung cancer screening in the randomized Prostate, Lung, Colorectal, and Ovarian (PLCO) Cancer Screening Trial. J Natl Cancer Inst. 2010;102(10):722-31.

21. Holme $\mathrm{O}$, Loberg $\mathrm{M}$, Kalager $\mathrm{M}$, et al. Long-term effectiveness of sigmoidoscopy screening on colorectal cancer incidence and mortality in women and men: a randomized trial. Ann Intern Med. 2018;168(11):775-82.

22. Holme $\mathrm{O}$, Loberg M, Kalager M, et al. Effect of flexible sigmoidoscopy screening on colorectal cancer incidence and mortality: a randomized clinical trial. JAMA. 2014;312(6):606-15.

23. Holme $\mathrm{O}$, Loberg $\mathrm{M}$, Kalager $\mathrm{M}$, et al. Long-term effectiveness of sigmoidoscopy screening in women and men. Ann Intern Med. 2018;169(9):663-4.

24. National Lung Screening Trial Research T, Aberle DR, Adams AM, et al. Reduced lung-cancer mortality with low-dose computed tomographic screening. N Engl J Med. 2011;365(5):395-409.

25. Pinsky PF, Miller E, Prorok $P$, et al. Extended follow-up for prostate cancer incidence and mortality among participants in the Prostate, Lung, Colorectal and Ovarian randomized cancer screening trial. BJU Int. 2019; 123(5):854-60

26. Pinsky PF, Prorok PC, Yu K, et al. Extended mortality results for prostate cancer screening in the PLCO trial with median follow-up of 15 years. Cancer. 2017;123(4):592-9.

27. Sandblom G, Varenhorst E, Lofman O, et al. Clinical consequences of screening for prostate cancer: 15 years follow-up of a randomised controlled trial in Sweden. Eur Urol. 2004;46(6):717-23 discussion 724.

28. Sandblom G, Varenhorst E, Rosell J, et al. Randomised prostate cancer screening trial: 20 year follow-up. BMJ. 2011;342:d1539.

29. Schoen RE, Pinsky PF, Weissfeld $J$, et al. Colorectal-cancer incidence and mortality with screening flexible sigmoidoscopy. N Engl J Med. 2012; 366(25):2345-57.

30. Schroder FH, Hugosson J, Roobol MJ, et al. Screening and prostate-cancer mortality in a randomized European study. N Engl J Med. 2009;360(13):1320-8.

31. Schroder FH, Hugosson J, Roobol MJ, et al. Screening and prostate cancer mortality: results of the European Randomised Study of Screening for 
Prostate Cancer (ERSPC) at 13 years of follow-up. Lancet. 2014;384(9959): 2027-35.

32. Andersson I, Aspegren K, Janzon L, et al. Mammographic screening and mortality from breast cancer: the Malmo mammographic screening trial. BMJ. 1988;297(6654):943-8.

33. Alexander FE, Anderson TJ, Brown HK, et al. 14 years of follow-up from the Edinburgh randomised trial of breast-cancer screening. Lancet. 1999, 353(9168):1903-8.

34. Moss SM, Wale $C$, Smith $R$, et al. Effect of mammographic screening from age 40 years on breast cancer mortality in the UK Age trial at 17 years' follow-up: a randomised controlled trial. Lancet Oncol. 2015;16(9):1123-32.

35. Segnan N, Armaroli P, Bonelli L, et al. Once-only sigmoidoscopy in colorectal cancer screening: follow-up findings of the Italian Randomized Controlled Trial--SCORE. J Natl Cancer Inst. 2011;103(17):1310-22.

36. Miller EA, Pinsky PF, Schoen RE, et al. Effect of flexible sigmoidoscopy screening on colorectal cancer incidence and mortality: long-term follow-up of the randomised US PLCO cancer screening trial. Lancet Gastroenterol Hepatol. 2019;4(2):101-10.

37. Pinsky PF, Yu K, Kramer BS, et al. Extended mortality results for ovarian cancer screening in the PLCO trial with median 15years follow-up. Gynecol Oncol. 2016;143(2):270-5.

38. Royston P, Parmar MK. An approach to trial design and analysis in the era of non-proportional hazards of the treatment effect. Trials. 2014;15:314.

39. Royston P, Parmar MK. Augmenting the logrank test in the design of clinical trials in which non-proportional hazards of the treatment effect may be anticipated. BMC Med Res Methodol. 2016;16:16.

40. Royston P. Power and sample-size analysis for the Royston-Parmar combined test in clinical trials with a time-to-event outcome. Stata J. 2018; 18(1):3-21.

41. Royston P, Choodari-Oskooei B, Parmar MKB, et al. Combined test versus logrank/cox test in 50 randomised trials. Trials. 2019;20(1):172.

42. Karrison TG. Versatile tests for comparing survival curves based on weighted log-rank statistics. Stata J. 2016;16(3):678-90.

43. Jacobs IJ, Menon U, Ryan A, et al. Ovarian cancer screening and mortality in the UK Collaborative Trial of Ovarian Cancer Screening (UKCTOCS): a randomised controlled trial. Lancet. 2016;387(10022):945-56.

44. Menon U, Gentry-Maharaj A, Ryan A, et al. Recruitment to multicentre trials-lessons from UKCTOCS: descriptive study. BMJ. 2008;337:a2079.

45. Jacobs I, Gentry-Maharaj A, Burnell M, et al. Sensitivity of transvaginal ultrasound screening for endometrial cancer in postmenopausal women: a case-control study within the UKCTOCS cohort. Lancet Oncol. 2011;12(1):38-48.

46. UKCTOCS. Protocol for the United Kingdom Collaborative Trial of Ovarian Cancer Screening (UKCTOCS) and the Long Term Impact of Screening on Ovarian Cancer Mortality (LTFU UKCTOCS). 2020. http://ukctocs.mrcctu.ucl.a c.uk/media/1066/ukctocs-protocol_v90_19feb2020.pdf. Accessed 21 Jan 2021.

47. Royston P, Parmar MK. Flexible parametric proportional-hazards and proportional-odds models for censored survival data, with application to prognostic modelling and estimation of treatment effects. Stat Med. 2002; 21(15):2175-97.

48. Hanley JA, Njor SH. Disaggregating the mortality reductions due to cancer screening: model-based estimates from population-based data. Eur J Epidemiol. 2018;33(5):465-72.

\section{Publisher's Note}

Springer Nature remains neutral with regard to jurisdictional claims in published maps and institutional affiliations.

Ready to submit your research? Choose BMC and benefit from:

- fast, convenient online submission

- thorough peer review by experienced researchers in your field

- rapid publication on acceptance

- support for research data, including large and complex data types

- gold Open Access which fosters wider collaboration and increased citations

- maximum visibility for your research: over $100 \mathrm{M}$ website views per year

At BMC, research is always in progress.

Learn more biomedcentral.com/submissions 